\title{
La argumentación lingüística, una guía para el estudio del alargamiento vocálico en aimara
}

\section{Linguistic argumentation, a guide for the study of vowel lengthening in Aymara}

\author{
Felipe Huayhua Pari \\ Universidad Nacional Mayor de San Marcos, Lima, Perú \\ https://orcid.org/oooo-0002-5788-4738 \\ fhuayhuap@unmsm,edu.pe
}

\begin{abstract}
Resumen
En el presente trabajo presentamos el alargamiento vocálico dentro del marco de estado metodológico de la argumentación gramatical según Botha (1970).

De una veintena de isoglosas que separa el aimara del norte (Umasuyu) del aimara del sur (Orcosuyo), el alargamiento es una de las isoglosas más representativas. Por su naturaleza el alargamiento no es un fonema sino el producto de cinco factores a tomar en cuenta: 1) elisión de consonantes continuas entre vocales iguales y diferentes, 2) alargamiento en grupo de consonantes internas, 3) alargamiento en sufijos con dichas consonantes, 4) alargamiento en palabras compuestas y 5) el reanálisis como falso alargamiento.
\end{abstract}

Palabras clave: alargamiento vocálico, argumentación gramatical, variación dialectal, reanálisis.

\begin{abstract}
In this paper we present the vowel lengthening in the framework of the methodological state of the grammatical argumentation according to Botha (1970). From twenty isoglosses that separate the northern Aymara (Umasuyu) from the southern Aymara (Orcosuyo), lengthening is one of the more representative isoglosse. By its nature, lengthening is not a phoneme but the product of five factors to take into account: 1) elition of continuous consonants between equal and different vowels, 2) lengthening in a group of internal consonants, 3) lengthening in suffixes with those consonants, 4) lengthening in compound words and 5) reanalysis as false lengthening.
\end{abstract}

Keywords: vowel lengthening, grammatical argumentation, dialectal variation, reanalysis. 


\section{Introducción}

En este trabajo apretado vamos a presentar un fenómeno de la lengua aimara, el alargamiento vocálico, que se produce por compensación con/sin monoptongación, por sandhi externo, por sandhi interno, por préstamos con reanálisis.

Los estudios existentes se han preocupado de los aspectos fonológicos, morfológicos sincrónicos; pero esta lengua presenta formas idiosincráticas, ciertas particularidades que con razón Hardman llamó «postulados», la riqueza de esta lengua se observa más en la forma oral que la escrita ya sea en el campo de la etnocultura y etnosemántica.

Las manifestaciones bibliográficas nos demuestran que los autores recogen las vocales alargadas de cada lugar de mayor conocimiento, donde hay una regularidad ya que los fenómenos que tocaremos ahora son reflejos de esta naturaleza, como advertimos sobre los usos de ultracorrección, generalización de las formas alargadas y no alargadas.

La influencia del español ha contribuido en acrecentar las formas alargadas en un contexto llamado secuencia de segmentos, estas se encuentran en préstamos de la pronunciación de las vocales medias españolas, sobre las vocales alofónicas del aimara, dándose como diptongos y triptongos.

Para algunos la vocal larga también forma parte de la variación lingüística en aimara.

La vocal larga es escrita de diferentes formas como: aa, , , a: en el alfabeto oficial de 1983 se optó por una vocal con diéresis, y en la forma fonética y fonológica es [a:], nosotros estaremos usando estas dos formas ya sea a nivel grafémico como a nivel fonético y fonológico.

El problema que motivó la presente investigación fue el siguiente: ¿el alargamiento vocálico en aimara es fonema o producto del proceso lingüístico? ¿Es predecible y condicionada o libre?

Dada esta interrogante, no propusimos como objetivos los siguientes: 1) analizar el alargamiento vocálico en diferentes contextos. 2) Presentar en el corpus escrito y oral la vocal alargada y el acento para ver si es predecible o libre.

Cabe precisar que la variable que articula nuestro análisis es el alargamiento vocálico.

Así mismo, definimos nuestra hipótesis orientadora como sigue: la vocal alargada en aimara no es fonema. Es una vocal alargada condicionada.

130 Lengua \& Sociedad, vol. 18, n. ${ }^{\circ}$ 1, Lima, enero-junio de 2019 
La argumentación lingüística, una guía para el estudio del alargamiento...

\section{Antecedentes}

La lengua aimara, en el ámbito peruano, comprende dos divisiones frontales. Por un lado, las formas habladas al norte del lago Titicaca, la gran región histórica de Umasuyu, y el otro, al sur del lago Titicaca, la otra gran región histórica de Orcosuyo. En la primera, al norte del lago, existe poca o nula presencia de vocales largas, ausencia del sufijo-waya, Incluso están presentes muchas y otras isoglosas más como las formas del enunciado que son reconocidas por sus hablantes como: «muxsa aymara» 'aimara dulce' o "pukina aymara» 'aimara de Puquina” porque el habla es más pausada y lenta, donde las expresiones largas se reconocen con claridad, sin complicaciones. Las palabras a las que se puede considerar que tienen alargamiento, en esta región, son pronunciadas con vocal corta inconscientemente. Es decir, el uso de la vocal larga es poco funcional. Esto ocurre en Conima. Así también, en la región norte, comprende las provincias de Huancané, Moho, parte de Putina y parte de Sandia.

En el lado opuesto, en las provincias de Chucuito, el Collao, Yunguyo y Puno está extendido el uso de frases con vocal alargada de carácter superficial o fonético. A este uso, la gente lo reconoce como: «ch'aphaqa aymara» 'aymara soso' o «lupi jaqi aymara» 'aymara de Lupaca', que por el uso frecuente de las alargadas llegan a la ultracorrección, o reanálisis. Así tenemos palabras con el acento en la penúltima sílaba, las frases enfáticas, entonacionales, estilísticas pronunciadas y escritas con vocal alargada que, en vez de solucionar el problema, complicarán más la estructura de la lengua.

Esta división casualmente coincide con la geografía. A ello hay que agregar, la historia dada de la expansión del Proto Aru, cuando en el siglo xin ingresó al altiplano Colla de los Puquinas, Umasuyu. Un grupo se dirigió hacia los flancos de la sierra de Arequipa, Santa Lucía, Puno, Huancané, e incluso llegan a Oruro. El otro grupo a Orcosuyu por los flancos de la costa, Moquegua, Tacna, abarcando parte de la sierra como es Puno, Chucuito, El Collao, Yunguyo, Bolivia y Chile. Esta división mantenía como frontera al lago Titicaca. Los incas ya tenían direccionado el Capac Nan a esos dos ramales. Estos son testigos silenciosos de años de historia de una red caminera de pueblos y lenguas que recorrieron Tunupa, Wiracocha; aunque más tarde «el Perú fue traicionado por sus caminos», como dice Hagen (1952, p. 5), porque brindó una vía directa de acceso al núcleo de su imperio. Por su parte, Cristóbal Vaca de Castro, en 1543, hizo construir tambos orientados en esas dos direcciones: uno hacia el Umasuyu que se separa en Qupuja y continúa hacia Chiquicachi (Samán) - Huancané - Moho - Huaycho - Carabuco - Achacachi 
- Guarina - hasta Paria; y el otro hacia Orcosuyu, que continua hacia Pucará Nicasio - Camata - Caracoto - Paucarcolla - Puno - Chucuito - Acora - Hilave hasta Aullaga (Vaca de Castro, 1543, pp. 44-49). El poco o mayor contacto con el español es facilitado con la penetración de las vías de comunicación, la escuela, las organizaciones políticas. Como reflejo de esta situación desigual tenemos una variedad que conserva sus rasgos y la otra variedad que está en constante innovación. Aquí la diferencia dialectal:

\begin{tabular}{l|l|l}
\hline Aimara del norte (Umasuyu) & Aimara del sur (Orcosuyu) \\
\hline chayaka & cha: ka & 'tallo de quinua' \\
\hline qalawasina $\sim$ qalawsina & qala: sina & 'por ser piedra' \\
\hline ñaña & ña: & 'casi' \\
\hline churamama & chura: ma & 'te daré' \\
\hline paqallqu & pa: qallqu & 'siete' \\
\hline lla: tunka $</$ llallatunka/ & lla: tunka & 'nueve' \\
\hline chika-uru chikawru & chiku: ru & 'mediodía' \\
\hline saranta $</$ saranata/ & sara: ta & 'tú irás' \\
\hline saranja $\sim$ saraja & sara: & 'yo iré' \\
\hline khitisa? & khiti $: ?$ & ‘Quién es?' \\
\hline qalayatha & qala: ta & 'yo soy piedra' \\
\hline qalayayatha & qalá: ta & 'yo era piedra' \\
\hline khaya uta saraja & khá: ut sará: & 'iré a aquella casa' \\
\hline jaqi kankatha & jaqi: ta & 'yo estoy como hombre' \\
\hline uta-aja $\sim$ uta-axa utayxa & uta: ja uta:xa & 'lado de la casa' \\
\hline asiru [asíru] & así: ru & 'culebra' \\
\hline asukara & asuka: ra & 'azúcar' \\
\hline
\end{tabular}

Como podemos observar, las vocales largas son predecibles. En el primer grupo no se observa este rasgo, mientras en el segundo grupo este rasgo se generaliza, tanto en la pérdida de siete consonantes como: /w/, /y/, /ñ /, /m/, /ll/,/n/, /j/, como en palabras compuestas, verbalización, tiempo pasado, tiempo futuro y préstamos que veremos más adelante.

Sobre la lengua quechua, Gustavo Solís decía: «Específicamente la cantidad vocálica está relacionada a debilitamiento o a elisión consonántica. Los segmentos consonánticos involucrados en uno u otro proceso son: /y/, /q/, /n/, /w/ y muy probablemente también -/r/» (Solís, 1996, p. 35). 
La argumentación lingüística, una guía para el estudio del alargamiento...

Gustavo Solís (1996) en su obra Los orígenes de la cantidad vocálica en quechua, presenta un panorama amplio sobre este fenómeno: monoptongación con nivelación, monoptongación sin nivelación o debilitamiento, segmentos que producen alargamiento vocálico, los préstamos y su refonologización. Así en sus conclusiones manifiesta: «nuestra posición sobre el problema de la duración vocálica implica reconocer que los datos apoyan ampliamente la hipótesis de la naturaleza derivada del alargamiento vocálico en quechua»; pero más adelante sostiene: «Por razones prácticas, ausencia de cognadas en otro dialecto (lenguas del quechua), la hipótesis en mención no puede ser validada completamente»...

"Varias hipótesis han sido presentadas para explicar la vigencia de la cantidad vocálica en quechua, tales hipótesis pueden ser sustanciales así:

a. El proto-Quechua presentaba oposición subyacente por alargamiento vocálico.

b. La cantidad vocálica es derivada:

- De vocales geminadas (monoptongación)

- De debilitamiento y/o elisión consonántica (con posterior monoptongación).

Procesos de debilitamiento y/o elisión de las consonantes mencionadas en el numeral 2 pueden explicar la mayoría de casos de longitud presente en la lengua; pero, lamentablemente no dan cuenta de todas las instancias. El resto de las muestras quedan para ser explicadas por otros factores: elisión de alguna consonante desconocida, préstamos, simbolismo fonético, etc. Respecto a este punto, y en consonancia con la característica predictiva de toda hipótesis, es preferible asumir que el alargamiento vocálico distintivo en quechua deriva, primariamente, de un proceso de elisión consonántica del ambiente entre vocales semejantes, las mismas que coalescen en un solo segmento vocálico largo. (Solís, 1996, pp. 38-39)

La productividad de la vocal larga, como se ha mencionado en mi tesis (Huayhua, 1991, pp. 18, 24-29) y en la Gramática (Huayhua, 2001, pp. 85-93), se explica por procesos morfofonológicos, donde se presentan ciertos condicionamientos fonológicos, morfológicos y sintácticos que crean el cambio a veces con alargamiento compensatorio y otras veces sin este como la monoptongación.

Bertonio $(1602,1613)$ presentó esas diferencias, «los lupacas dicen thaa maa y los pacases dicen thaya, maya». Hardman (1974) y Martín (1974) mencionan la única presencia de par mínimo cha: ka / chaka, como veremos más adelante. 


\section{Felipe Huayhua Pari}

\section{Marco teórico}

Esta forma es una adaptación de las lenguas que poseen diptongos, ya sean crecientes o decrecientes, donde existe monoptongo proveniente de un poliptongo, con la coalescencia de las vocales por razones históricas como:

$$
\begin{aligned}
\text { ai }>0 & \text { baisu [baysu] beso } \\
\text { au }>0 & \text { aurum [awrum] oro }
\end{aligned}
$$

Sanford A. Schane presenta la coalescencia de consonantes, vocales y manifiesta:

\footnotetext{
Dos consonantes contiguas son reemplazadas por una simple que comparte rasgos de las dos primeras [...] ai y au latinas se convirtieron en e, o en romance, respectivamente, puesto que la coalescencia o fusión fonemática, implica tanto la asimilación como la reducción, muchos de estos ejemplos podrían describirse como la acción conjunta de estos dos procesos. (Schane, 1979, pp. 81-91)
}

$\mathrm{Al}$ respecto, sabemos que en aimara no existe diptongos entendidos como secuencia de vocales; lo que hay, como hemos indicado, es la secuencia de vocal y semivocal.

El alargamiento compensatorio es una forma de monoptongación que resulta en la reducción de un diptongo o secuencia vocálica en una vocal, con alargamiento «las lenguas casi invariablemente adquieren alargamiento vocálico a través del desarrollo de secuencias de vocales en hiatos (secuencia de vocales geminadas) estos resultan del debilitamiento de uno o más consonantes intervocálicas» (De Chene et al., 1979, p. 520). Asimismo, estos autores demuestran que el debilitamiento de un segmento consonántico entre vocales idénticas produce indefectiblemente vocal larga.

Alargamiento compensatorio exótico, lo llama así, Jean-Mare Beltzung en su tesis doctoral "Lallongemet compensatoire dan les representationes phonologiques-nature contraints et typologic». Esto es: ACI el alargamiento compensatorio por elisión de un segmento en posición intervocálica, $\mathrm{vCv} \rightarrow \mathrm{v}$ : (Beltzung, 2008, pp. 120,119). Así mismo, otro tipo es: ACPI el alargamiento compensatorio por elisión de un segmento en posición inicial de grupo consonántico $\mathrm{CCV} \rightarrow \mathrm{v}$ : (Beltzung, 2008, pp. 130, 131).

Con esto estamos frente a tres tipos de alargamiento en aimara. El primero aparece cuando el segmento que se evapora está entre vocales iguales. El segundo es cuando el segmento que se elide está en inicial del grupo consonántico. Para ambos tipos valen estas dos fórmulas:

134 Lengua \& Sociedad, vol. 18, n. ${ }^{\circ}$ 1, Lima, enero-junio de 2019 
La argumentación lingüística, una guía para el estudio del alargamiento...

a. $\quad \mathrm{V}_{\mathrm{I}} \mathrm{CV}_{\mathrm{I}} \rightarrow \mathrm{V}$ : maya $>$ ma:

b. $\quad \mathrm{CCV} \rightarrow \mathrm{v}: \mathrm{CV}$ compadre > kumpa: ri

asiyru > asi: ru

El tercer tipo se da, si el segmento está entre vocales diferentes, así:

c. $\quad \mathrm{V}_{\mathrm{I}} \mathrm{CV}_{2} \rightarrow \mathrm{v}:$ Ciy̌ara $\rightarrow$ ca: ̌ra

«In other languages, variations in length may be used contrastively. Long vowels contrast with short, vowels in many languages-for example, Estonian, Finnish, Arabic, and Japanese» (Ladefoged, I993, p. 250). Con ello podemos plantear que ya no se trata de dos segmentos, sino de un segmento /v:/. No sabemos si en esas lenguas fue producto de un proceso o es genuino.

Tomando estas referencias teóricas como patrón de análisis, en aimara, se observa el alargamiento tanto al interior de la raíz, en el nivel intermorfémico o juntura interna o sandhi interno (raíz-sufijo). Según define Matthews (I980, p. I22), el sandhi interno «opera dentro de tales límites», y el sandhi externo «opera entre límites de palabra», como a nivel transléxico o juntura externa o sandhi externo (raíz-raíz). Las semiconsonantes /w/ /y/ se muestran como diptongos cuando están seguidos de vocales.

Laura Martín (1974), en «Fonología», Cap. III del Compendio poco dice del alargamiento vocálico. Según esta autora, hay alargamiento fonémico simple, alargamiento gramatical, reducción de /aya/ y alargamiento paralingüístico, tal como lo declara: «El alargamiento vocálico en aymara es fonémico. Los problemas que se suscitan en una exposición de la distribución del alargamiento vocálico son bastante complejos. Parece que existe varios tipos de vocales largas» (Martín, I974, p. 39). La autora no explica otros casos como en ura: xiw 'ya es hora', aquí es verbalización aksa: xar 'a este lado' que puede ser de -wxa : xa.

Martha Hardman (1983), en el artículo publicado por la revista IJAL 49:2 pp. I86-I95 como: «Jaqaru short vowels» — que tradujimos como las vocales cortas del jacaru - hace una mención al respecto, tanto en jacaru como en aimara, señalando que siempre tenían referencia de vocal larga. Para la autora, la carga funcional es pequeña, muy restringida, es «asunto de acento secundario» como K'aka = tío, Kaka = ala, donde la vocal larga de jacaru no corresponde a la vocal larga de aimara. Manifiesta que en aimara, el uso del alargamiento es más amplio, así señala que existen condicionamientos gramaticales como la reducción de las sílabas -wa, -ya, por composición q" i pa + uru = q" i pu:ru, e 
incluso es paralingüístico qawq"a: xisa: =¿cuánto es?. También indica que se desconoce su presencia en la raíz, sólo se conoce el caso de cha:ka = tallos secos /chaka = puente".

Rodolfo Cerrón-Palomino (1994) en su artículo «Vocales largas en Jacaru: reconsideración» publicado en la revista Language in the Andes, Lexis, cuestiona la referencia de Hardman, pues no hay alargamiento con la vocal /i/, solo con la vocal /a/, y /u/. En 2001, en su libro Lingüística aimara, página 171, CerrónPalomino dice que en jaqaru el alargamiento es superficial de variación alofónica, derivada y de naturaleza compensatoria y sólo ocurre a nivel léxico. En base al diccionario de Nelly Belleza, él encontró diez raíces con alargamiento: con vocal /a:/, ocho casos; con /u:/, dos casos y ninguna con /i/. Cinco son préstamos del quechua, tres son cognados con aimara y sólo dos con alargamiento. Termina diciendo: «Pues bien, cualquiera que sea el origen del incremento cuantitativo en los ejemplos, todo parece indicar que aquí estamos ante un fenómeno claramente derivado y no ancestral» (Cerrón-Palomino, 200o, p. 172)

Por nuestro lado, en Huayhua (2001), apreciamos que el AV es por compensación, coalescencia, monoptongación: «En resumen las V.L. se da por elisión en palabras compuestos, compensación, verbalización, tiempo pasado y futuro... no obstante es un problema...».

\subsection{Alargamiento compensatorio (con vocales iguales) o elisión (síncopa)}

Por medio de esta regla se da dos casos diferenciados. El primero, cuando el debilitamiento del segmento consonántico [+continuo] está entre vocales idénticas, se produce vocal alargada. En este caso el alargamiento es expresado por reglas fonológicas donde podemos apreciar: «I) qué segmento cambia; 2) cómo cambia; 3) bajo qué condiciones» (Schane, I979, p. IOI). Esta manifestación en lenguaje corriente, la podemos traducir a la siguiente notación formal: $\left[\mathrm{V}_{\mathrm{I}} \mathrm{C}_{\mathrm{I}} \rightarrow \mathrm{V}\right.$ : $]$. El segundo caso es cuando el alargamiento está relacionado al debilitamiento de la consonante glide [+ continuo] como en quechua: [vC $\rightarrow \mathrm{v}$ :].

Para el primer caso, son candidatos las siete consonantes /y/, /w/, /m/, /n/, /ñ/, /11/, /j/, cuyos ejemplos se presentan a continuación.

(1) La consonante /y/ como ejemplos podemos listar: aya $>$ a:

chayaka > cha: ka

'tallo seco'

136 Lengua \& Sociedad, vol. 18, n. ${ }^{\circ}$ 1, Lima, enero-junio de 2019 
La argumentación lingüística, una guía para el estudio del alargamiento...

\begin{tabular}{|c|c|}
\hline yayani > ya: ni & 'talentoso' \\
\hline patunka $<$ payatunka $>$ pa: tunka & 'veinte' \\
\hline qayaña > qa:ña & 'aporcar' \\
\hline yayaqa > ya: qa & 'obediencia' \\
\hline \multicolumn{2}{|l|}{ iyi > i: } \\
\hline asiyiru - a si: ru & 'culebra' \\
\hline ch'iyitu - ch'i: tu & 'me rompe' \\
\hline \multicolumn{2}{|l|}{ uyu > u: } \\
\hline juyula ju:la & 'arbol sauco' \\
\hline kuyurmi kuyu: rmi & 'arco iris' \\
\hline phuyusilla phu: silla & 'silbido' \\
\hline chhuyu chhu: & 'fresco' \\
\hline
\end{tabular}

Notaremos que las tres vocales están presentes en este contexto [V1Cv1], Bertonio $(1602,1613)$ ya reparaba en esta alternancia al mencionar que los Lupacas pronuncian thaa, paa, maa, mientras los Carangas pronuncian thaya, phaya, maya.

(2) Con la consonante /w/ son ejemplos: qalawasina - qala: sina 'por ser piedra'

Con las vocales i, u no tenemos realización de alargamiento en el corpus, parecen una excepción.

(3) Con la consonante $/ \mathrm{m} /$ apamama - apa: ma

No hay realización de alargamiento con vocales i, u en este contexto, solo es a nivel intramorfémico.

(4) Con la consonante $/ \mathrm{n} /$ saranata - sara: ta 'tu irás'

Solo presenta con la vocal a, en nivel intramorfémico o sandhi interno

(5) Con la consonante / $\tilde{n} /$ ñaña - ña: ñiñitu - ñi: tu 


\section{Felipe Huayhua Pari}

$\mathrm{Al}$ menos está presente con las dos vocales /a/, /i/; pero no hay con /U/

(6) Con la consonante /l1/ llallatunka - llatunka lla: tunka 'nueve'

No se ha encontrado el alargamiento con otras vocales i, u. Las palabras con /ñ/, /11/ son cambios analógicos como en Ollanta viene de Ulla-nta uña-nta 'mirar adentro', igual puede ser ñaña y llalla 'casi, cerca'

(7) Con la consonante $/ \mathrm{j} /$

$\begin{array}{ll}\text { ajara }>\text { a: ra } & \text { 'quinua silvestre' } \\ \text { saraja > sara: } & \text { 'yo iré' } \\ \text { jujuña }>\text { ju:ña } & \text { 'evaporar' }\end{array}$

Igualmente, no se ha encontrado con vocal $i$, aunque la palabra muju «semilla» dan como moho 'hongo' del castellano, si fuera superestrato tendríamos como mu: ya con /U/ alargada.

Además se ha encontrado con la consonante /r/ en janirara-jani:ra aunque este no está entre vocales iguales.

\subsection{Alargamiento compensatorio con vocales diferentes y consonante adyacentes}

En este grupo está como la monoptongación por coalescencia $\mathrm{v1C}(\mathrm{v} 2) \rightarrow \mathrm{v}$ :

Tenemos un solo ejemplo para esta fórmula

ch'iyara > cha:ra

\subsection{Grupo de consonantes con glides $w, y, r$ : cuya notación formal es VCCV > V:CV}

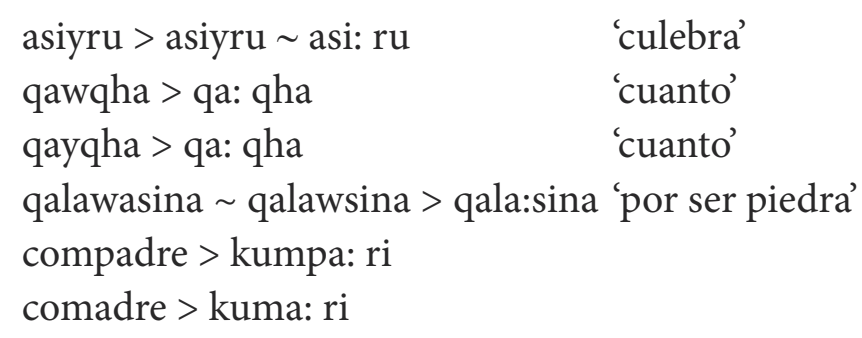

138 Lengua \& Sociedad, vol. 18, n. ${ }^{\circ}$ 1, Lima, enero-junio de 2019 
La argumentación lingüística, una guía para el estudio del alargamiento...

$$
\begin{aligned}
& \text { isidro }>\text { isi: ru } \\
& \text { pudre }>\text { pu: ri } \\
& \text { pobre }>\text { puyri } \sim \text { pu: ri } \\
& \text { ladrón }>\text { lawruna } \sim \text { la: runa }
\end{aligned}
$$

En estos ejemplos, podemos ver que ya no son con vocales idénticas, sino grupo de consonantes con glides $\mathrm{w}, \mathrm{y}$. Los préstamos del castellano que presentan grupo consonántico dr, br entran en este juego.

\subsection{Sufijos que presenta sílaba}

$$
\text { -ya, -wa, -ma, -na, -ja -ra }
$$

$\mathrm{Al}$ formarse las palabras con sufijos -ya, -wa que son verbalizaciones de nombres; en las formas nominales incluso con sufijos independientes -ki, -raki, -puni; y en las formas verbales en tiempo -ya pasado y -na futuro, la estructura resultante se presenta como en el primer caso. Es decir, se repite la regla de alargamiento compensatorio a ese nivel de juntura o sandhi interno Raíz+Sufijo con consonante inicial y no con vocal inicial. En este caso, sólo es coalescencia que termina en monoptongación con «elisión y prodelisión», "por regla general, lo decisivo es el dominio y no la posición» (Matthews, 1980, p. 123)
a. chacha-ya-tha $>$ chacha: tha 'yo soy hombre'
b. apa-i $>$ api 'ell lleva'
c. ichu-i '> ichu lleva en el brazo'

En a) se presenta alargamiento vocálico intramorfémico o en sandhi interno.

En b) se presenta monoptongación por coalescencia, porque la lengua aimara no admite diptongos, así presenta elisión de vocal temática ante el morfema $\{-i\}$ de tercera persona, como elisión morfológicamente condicionada (Huayhua, 200I, p. I03).

En c) presenta monoptongación por prodelisión, porque en aimara se presenta la vocal /U/ como más dominante. «En términos fonéticos las vocales sonoras velares y más abiertas vencen a las menos sonoras medias/cerradas y palatales»» como decía Matthews (I980, p. I23) con respecto a Sandhi en griego o juntura (en este caso tanto a), b) presenta diptongo lo cual se monoptongiza. 


\section{Felipe Huayhua Pari}

\section{Sufijo $\{$-ya $\}, /-w a /$}

Este sufijo /-ya/ que indica ser un verbalizador como /-wa/, también señala tiempo pasado y por ello pueden darse los dos a la vez. En Bolivia han optado por la forma antigua como la forma innovada en la escritura. Así -ya $\sim$-wa $>-$ : ya:
chacha - ya - ta chacha: ta
'tú eres hombre'
sara - ya - ta sara: ta saraya: ta 'tú fuiste'
chacha - ya - ya - ta chacha-:-:-ta > chacha: ta chacha:yata 'tú fuiste hombre'
qalawasina qala: sina 'por ser piedra'
qalawa - ya - sina $\sim$ qala-wa: -sina $\sim$ qala: sina 'por haber sido piedra'
jiwa - ta - ya - ta jiwata: ta 'tú eres muerto, tu habías muerto'
jiwa - ta - ya - i jiwata: na 'él fue muerto'
sara-waya-ya-na sarawaya: na sarawa: na él había ido de pasada, al momento'

\section{Sufijo $\{$-ja $\}$}

En el tiempo futuro, la primera persona actora se ha reducido a la vocal alargada en la variedad de aimara sureño.

$$
\begin{aligned}
& \text { sara-na-tha } \rightarrow \text { sarantha } \rightarrow \text { saranja } \rightarrow \text { sarana, saraja }>\text { sara : 'yo iré' } \\
& \text { sara-na-ta } \rightarrow \text { saranta }>\text { sara: ta 'tú irás' }
\end{aligned}
$$

Aquí podemos ver que el sufijo -ja resultado de cambios (que Bertonio, 1603, presentó como sarahata 'tu irás'), se ha alargado como en: jujuña > ju: ña 'evaporar'

\section{Sufijo $\{-$ na $\}$}

Como presentamos en el ejemplo anterior, el tiempo futuro está marcado con /-na/ el cual ante el sufijo -tha, -ta pierde la vocal y a su vez se convierte en vocal alargada.

\section{Sufijo \{-mama}

Es sufijo de transición 'yo a ti', $1 \rightarrow 2$ en la variedad sureña se nota con alargamiento vocálico.

$$
\text { churamama 'yo te daré' > chura: ma }
$$


La argumentación lingüística, una guía para el estudio del alargamiento...

\section{Sufijo $\{$-rara $\}$}

Este sufijo también ha perdido la primera silaba -ra

$$
\text { janirara > jani: ra 'todavía no’ }
$$

\subsection{Monoptongación con alargamiento vocálico}

En la lengua aimara es importante apreciar las palabras compuestas, que pueden ser plenas, separadas yuxtapuestas, formas aglutinadas como el caso de palabras adverbiales de tiempo. Estas palabras presentan alargamiento vocálico cuando la raíz antecedente termina en vocal y la otra comienza con vocal, al fusionarse aparece como diptongo. Pero, en el caso del aimara, hay coalescencia de vocales por la prohibición de diptongos y luego la vocal se alarga con dominancia de vocal /U/ velar frente a las vocales /i/, /a/ y de la vocal/i/frente a la vocal /a/. [RV + vR $\rightarrow \mathrm{RV}: \mathrm{R}$ ó $\mathrm{VCV}+\mathrm{VCV} \rightarrow \mathrm{VCV}: \mathrm{C}]$

Se presenta nueve posibilidades en la frase adverbial, como:

$\begin{array}{ll}\text { aa }>\text { a: nayra aruma }>\text { nayra: ruma } & \text { 'anoche antiguo' } \\ \text { ai }>\text { i: masa inti }>\text { masi: nti } & \text { 'ante del día solar' } \\ \text { au }>\text { u: nayra uru }>\text { nayru: ru } & \text { 'antes' } \\ \text { ia }>\text { i: jurpi aruma }>\text { jurpi: ruma } & \text { 'anteanoche' } \\ \text { ii }>\text { i: jurpi inti }>\text { purpi: nti } & \text { 'pasado el sol' } \\ \text { iu }>\text { u: jurpi uru }>\text { jurpu: ru } & \text { 'día anterior' } \\ \text { ua }>\text { u: muru aqu }>\text { muru: qu } & \text { 'arena repleto, ahora cero' } \\ \text { ui }>\text { u: uru inti }>\text { uru: nti } & \text { 'sol en pleno día' } \\ \text { uu }>\text { u: muru uta }>\text { muru: ta } & \text { 'casa sin dos aguas' }\end{array}$

\subsection{Reanálisis de vocal alargada}

Se podía observar que, en algunas partes, los autores de los textos revisados se preocupaban en escribir el acento. Esto se nota por la vocal alargada. A veces, escribían innecesariamente, otras veces por falta del conocimiento del alargamiento no apreciaban su presencia, como ocurre en los textos actuales. A este fenómeno le llamo ultracorrección; aunque tal vez sea más adecuado denominarlo reanálisis en préstamos y palabras acentuadas. Aquí presentamos algunos de las cincuenta palabras erradas. 
Felipe Huayhua Pari

\begin{tabular}{l|l|l|l}
\hline dice: & debe ser o decir: & dice: & debe decir: \\
\hline asuka: ra & asukara 'azucar' & kusta: la & Kustala 'costal' \\
\hline anata: wi & anatawi juego & k'uma: ra & K'umara 'sano' \\
\hline inaski: ri & ina: skiri quieto & la: si & lasi 'familia' \\
\hline inaska: ña & ina: skaña ser quieto & manq'ayaja: wa & manq'ayajawa 'haré comer' \\
\hline isa: ñu & isañu mashua & mima: ra & mi: mara 'año pasado' \\
\hline jach'axa: ta & jach'a: xa: ta cuando seas grande & nikha: ra & ni: khara 'antes' \\
\hline ja: lla & jalla viva & pala: sa & palasa 'plaza' \\
\hline ji: sa & jisa si & parti: ra & partira 'partida' \\
\hline jiri: ru & jiriru herrero & pira: sa & pirasa 'peras' \\
\hline kiswa: ra & kiswara quishuar & rama: ra & ramara 'ramada' \\
\hline ispañula: & ispañula español & siwa: ra & siwara 'cebada' \\
\hline
\end{tabular}

Hasta en sufijos suelen poner innecesariamente la vocal alargada como: -xa: si, -w: cha, -ti:, -pi:, -:wi.

En este caso, ningún dato cumple las reglas mencionadas en 1), 2), 3), 4) y 5), se debe al acento fijo, fonético que es predecible en la penúltima sílaba, un acento prosódico y no fonológico, ni ortográfico. Aunque en jacaru el acento está en la primera silaba, aun así, sigue siendo predecible. Como se puede cotejar en vez de acento perciben como vocal alargada y otros serán de carácter paralingüístico.

Existe una situación de carácter psicolingüístico. Cuando el hablante posee un segmento, adquiere la conciencia fonológica y al admitir préstamos los adorna con esos segmentos. Por ejemplo, el quechua sólo conoce mikuy que es comer; pero si la variedad posee las laringalizadas como sustrato aimara, pronuncia mikhuy con aspirada. Esa misma situación puede ser en los préstamos como azúcar, plaza, yungas, que pronuncian en aimara como [asukára], [palása], [yunkása] y escriben como asuka: ra, pala: sa, yunka: sa, con alargamiento, cuando es falso esa forma de escribir.

Nuestra propuesta es que el acento prosódico en la penúltima silaba no debe confundirse con la vocal alargada. Se debe escribir con alargamiento vocálico donde la regla exige y no donde es innecesario. Aquí presentamos la otra cara:

142 Lengua \& Sociedad, vol. 18, n. ${ }^{\circ}$ 1, Lima, enero-junio de 2019 
La argumentación lingüística, una guía para el estudio del alargamiento...

\begin{tabular}{l|l|l}
\hline Dice: & Debe decir: & 'tiene que ser obediente' \\
\hline yaqatañapa & ya: qata: ñapa & 'era necesario' \\
\hline wakisiritayna & waksiri: tayna & 'mayor' \\
\hline jiliri & jili: ri $\sim$ jilayri & 'al ser chuño' \\
\hline ch'uñutaxipana & ch'uñuta: xipana & 'ya debe ser pisado' \\
\hline takirañaxiwa & takiraña: xiwa & 'para que sea bueno' \\
\hline sumañapataki & suma: ñapataki & 'ya está pelado' \\
\hline sillp'irataxiwa & sillp'irata: xiwa & 'otro también' \\
\hline mayniriraki & mayni: riraki & 'tenía dinero' \\
\hline jawart'iritu & qullqini: tayna & 'me cantó \\
\hline yuqallaskirita & jawart'iri: tu & 'cuando aún era muchacho' \\
\hline uñt'asiribxataynawa & yuqalla: skiri: ta & 'se habían conocido' \\
\hline & uñt'asiri: pxatayna &
\end{tabular}

En estos casos debe presentar verbalización de la forma nominal.

\subsection{Alargamiento paralingüístico}

En los textos escritos de Elen Ross (1953), Deza (1992), Ayala (1988), Salt Lake (1978) y MINEDU, aún persiste la idea de que en aimara hay acento y lo escriben con vocal alargada así:

$\begin{array}{ll}\text { maymarap } \ddot{i} & \text { ¡año pasado es pues! } \\ \mathrm{t} \ddot{i} & \text { caverna } \\ \text { ampi } & \text { no cierto } \\ \text { jall } \ddot{a} & \text { ¡viva! } \\ \text { inakip } \ddot{i} & \text { ¡gratis pues! } \\ \text { kunas } \ddot{a} & \text { ¿qué es? } \\ \text { parlapxaraktasa: } & \text { ¡han convocado ya! } \\ \text { janit } \ddot{i} & \text { ¿no? }\end{array}$

Como Martha Hardman dice: «El alargamiento de una vocal en cualquier sílaba puede ocurrir como resultado de fenómenos paralingüísticos que parecen acompañar a expresiones de sorpresa, énfasis o súplica» (Hardman, 1988, p. 40). Edwar Sapir en su obra Lenguaje, manifestaba que las formas onomatopéyicas, interjectivas, interrogativas, admirativas violan las reglas lingüísticas, porque son extralingüísticas y no propiamente lingüísticas. Bajo estas observaciones, los 
ejemplos que presentamos en su mayoría son interjectivas, interrogativas cuyo acento o alargamiento, como se aprecia, indica ese estilo. La entonación de interrogación puede variar según la variedad. Así, para decir ¿es gratis nomás?, en Conima pronuncian ¿ínakiti?; en Huancané, ¿inakiti? y en Juli, ¿inakití? Una vez más, tanto el acento como el sufijo -ti identifican la interrogación. La pregunta es cuántos tipos de acentos se puede establecer, aunque escriban con vocal alargada. O como aseveraba Hardman sin dar ejemplos, hay varias clases de vocales alargadas. Como las formas interjectivas, interrogativas las escribimos con signos correspondientes, eso ya sería salvaguarda de las formas alargadas y del acento. La pregunta que queda es ¿estos tipos de palabras paralingüísticas o extralingüísticas seguirán escribiéndose con acento o vocal alargada? La respuesta es difícil. Por mi parte, diría que no, pues sólo es cuestión de estilo. Otros afirman que es necesario identificar con acento ya sea primario, secundario (') o sino con vocal alargada para mantener el estilo, la pronunciación como kunásá, kunása:, kunasá, etc”

\section{Estructura de una argumentación lingüística}

Bajo la argumentación lingüística de Rudolph P. Botha (1970) podemos guiarnos en seis aspectos para la validación de nuestro tema de investigación: $1^{\circ}$ postulado-conclusión, $2^{\circ}$ datos o corpus, $3^{\circ}$ garantizador, $4^{\circ}$ calificador, calidad, $5^{\circ}$ refutabilidad y $6^{\circ}$ retorno o fundamento.

\subsection{Postulado-Conclusión}

Como enunciado de un dato o hecho del que se afirma o niega su corrección o incorrección. Otras denominaciones, afirmación, hipótesis, tesis, conjetura, suposición.

En nuestro estudio, la hipótesis que nos planteamos es: la vocal alargada en aimara no es fonema, es generada mediante de procesos morfofonémicos.

Como conclusión estamos presentando que hay cuatro indicadores sobre alargamiento:

Es alargamiento compensatorio, cuando el segmento (consonante + continuo) que se evapora, está entre vocales idénticas $\mathrm{V}_{\mathrm{I}} \mathrm{CV}_{\mathrm{I}} \rightarrow \mathrm{v}$ :. Cuando está entre vocales diferentes $\mathrm{V}_{\mathrm{I}} \mathrm{CV}_{2} \rightarrow \mathrm{v}$ : . Cuando está en inicial del grupo consonántico, $\mathrm{VCCV} \rightarrow$ v: Cv. Sufijos con glides W, Y

144 Lengua \& Sociedad, vol. 18, n. ${ }^{\circ}$ 1, Lima, enero-junio de 2019 
La argumentación lingüística, una guía para el estudio del alargamiento...

Se presenta cuando los sufijos con dichas consonantes -ya, -ma, -na, -ja, -1la se evaporan.

En frases o palabras compuestas, para evitar secuencia vocálica hay coalescencia con predominio de /U/ frente a /i/, /a/; así como /i/ frente a /a/.

El acento prosódico es transcrito como vocal alargada en los préstamos y formas paralingüísticas. A nuestro juicio no debe ser alargada.

\subsection{Datos o Corpus}

Se trata de los hechos que se proveen para apoyar o contradecir un enunciado-conclusión.

Para el tema que tratamos, estamos presentando, para apoyar el postulado cinco aspectos de alargamiento:

\subsubsection{V1CV1 $\rightarrow$ V:}

«[C] uando el debilitamiento del segmento consonántico + continuo está entre vocales idénticas se produce vocal alargada». Para esto presentamos que las siete consonantes /y/, /w/, /m/, /n/, /ñ /, /ll/, /j/ entran en juego para cumplir la notación formal.

\subsubsection{V1CV2 $\rightarrow$ V:}

«[C]uando el debilitamiento del segmento consonántico está entre vocales diferentes» Para esto tenemos un ejemplo en aimara

$$
\text { Ciy̌ara } \rightarrow \mathrm{Ca} \text { : řa 'color negro' }
$$

\subsubsection{VCCV $\rightarrow \mathrm{V}: \mathrm{CV} / \ldots$}

«El alargamiento compensatorio por elisión de un segmento en posición inicial de grupo consonántico»

Para ejemplos presentamos que las consonantes que se evaporan son: /y/, /w/, /d/, /b/. Los dos primeros en palabras aimaras y los dos últimos en préstamos del español.

$$
\begin{array}{ll}
\text { asiyru }>\text { asi: ru } & \text { 'culebra' } \\
\text { qawqha } \sim \text { qayqha }>\text { qa: qha } & \text { '¿cuánto?' }
\end{array}
$$




$$
\begin{aligned}
& \text { ladrón }>\text { lawruna }>\text { la: runa } \\
& \text { pobre }>\text { puwri }>\text { pu: ri }
\end{aligned}
$$

\subsubsection{Sufijos que portan consonantes [+continuo]}

$$
\text { -ya, -wa, -ma, -na, -ja, -ra }
$$

En este caso se trata de palabras sufijadas que presentan una estructura como en (1) y aplica la regla de alargamiento compensatorio.

El verbalizador -ya. Cualquier nombre, adjetivo, adverbio, pronombre, formas nominalizadas y flexionadas, y que lleve sufijos independientes como -ki, -puni, -raki, si lleva sufijo verbal, antes debe verbalizarse con sufijo -ya o -: (alargamiento vocálico).

$$
\begin{aligned}
& \text { chachayatha > chacha: tha 'soy hombre' } \\
& \text { chachatakiyatha > chachataki: tha 'soy para hombre' } \\
& \text { chachakiyatha > chachaki: tha 'soy hombre nomás' } \\
& \text { chachapuniyatha }>\text { chachapúni: tha 'soy siempre hombre' } \\
& \text { chacha-rakiyatha > chacharaki: tha 'soy hombre también' }
\end{aligned}
$$

El verbalizador -wa. Este sufijo también llega evaporarse y aparece vocal alargada.

El tiempo pasado -ya. Este sufijo se convierte en vocal alargada. En Bolivia, a veces, consignan las dos a la vez.

sarayatha, > sara: tha, saraya: tha yo fui

sara-ya-i > sara-: -na 'el fue' (-na es morfema vacío)

El transitivo I $\rightarrow 2$ en futuro -ma. También se evapora y deja vocal alargada

$$
\text { chura - mama > chura: ma 'yo te daré' }
$$

El futuro -na. También al estructurarse como grupo consonántica entra elidirse. sara-na-tha $>$ sarantha $>$ saranha $>$ saraha $->$ sara:

El futuro -ja primera persona, como en el ejemplo anterior.

Adverbial -rara. Aparece últimamente/-r/; pero muy reducido en su aplicación: jani-rara > jani: ra 'aun no'

Como estos han surgido ya sufijo con alargamiento inicial en:

146 Lengua \& Sociedad, vol. 18, n. ${ }^{\circ}$ 1, Lima, enero-junio de 2019 
La argumentación lingüística, una guía para el estudio del alargamiento...

$$
\begin{array}{lll}
\text {-wja }>\text {-:ja } & \text { utawja > uta: ja } & \text { 'por la casa' } \\
\text {-wxa }>\text { :xa } & \text { utawxa }>\text { uta:xa } & \text { 'por la casa' }
\end{array}
$$

\subsubsection{Monoptongación con}

\section{alargamiento compensatorio}

Es otra de las secuencias vocálicas que se presentan en palabras compuestas adverbiales, al no permanecer separadas, hay coalescencia y monoptongación en vocal alargada, enteramente una vocal, un segmento y no dos. $\mathrm{R}_{\mathrm{v}}+{ }_{\mathrm{v}} \mathrm{R} \rightarrow \mathrm{R}_{\mathrm{v}}$ : ó $\mathrm{CV}+\mathrm{VC} \rightarrow \mathrm{CV}: \mathrm{C}$

Los ejemplos se muestran con las nueve posibilidades, con predominio de vocal /U/ frente a /i/, /a/, predominio de vocal /i/ frente a /a/

$$
\begin{aligned}
& U+a>U: \\
& U+i>U: \\
& U+U>U: \\
& i+a>i: \\
& i+i>i: \\
& i+U>U: \\
& a+a>a: \\
& a+i>i: \\
& a+u>U:
\end{aligned}
$$

\subsubsection{Reanálisis de vocal alargada}

En los textos escritos aparecen cerca de cincuenta palabras castellanas y quechuas que ingresan como préstamos al aimara. Están escritas con vocal alargada; pero solo la vocal que está en la penúltima sílaba. Otro caso similar se da en interjecciones.

$\begin{array}{ll}\text { asuka: ra } & \text { de azúcar } \\ \text { yunka: sa } & \text { de yunka } \sim \text { yunkas } \\ \text { kiswa: ra } & \text { de kiswar } \\ \text { ja: lla } & \text { 'tal vez' } \\ \text { ji: sa } & \text { ‘si! }\end{array}$

Nosotros pensamos que es un proceso de reanálisis, pues los aimaras al tener en su conciencia fonológica la vocal alargada la emplean para refonologizar estas 
palabras prestadas con alargamiento, cuando solo debe ser el acento fijo, prosódico y no ortográfico. Y no debería llevar vocal larga.

\subsection{Garantizador, inferencia/soporte (Warrant)}

Un enunciado hipotético de la forma «si X entonces y». es precisamente lo que autoriza la inferencia de 2 a partir de 1.

Para el caso de nuestra investigación, tenemos: Si el alargamiento vocálico es proceso morfofonológico predecible, entonces el alargamiento vocálico no es fonema.

Si el acento en la penúltima silaba es fonético, fijo, entonces la vocal que está en la penúltima silaba no es alargada: es vocal con acento prosódico o fonético.

\subsection{Ecualificador, calidad, modal (Qualifiers)}

Específica el grado de fuerza que los datos confieren al enunciado-conclusión es en virtud del garantizador.

En nuestro tema, según los datos indicados en el garantizador, absolutamente la vocal alargada no es fonema y el acento no puede ser confundido con vocal alargada.

\subsection{Condiciones de refutación o refutabilidad}

Define las condiciones bajo las cuales el garantizador no es válido, en las que su autoridad ha de ser desatendido; por lo tanto, en las que no sería lícito inferir de 1 a 2.

Para los resultados de nuestra pesquisa existe un contraejemplo aparente. Es el caso de cha: ka / chaka 'palo seco / puente'; pero cha: ka proviene de chayaka que está presente en la variedad norteña, en aimara de La Paz. En consecuencia, entre los morfemas en cuestión la oposición es aparente.

$$
\begin{array}{ll}
\text { qala: } & \text { 'yo seré piedra' } \\
\text { qala: } & \text { 'piedra' } \\
\text { pero: } & \text { qala-ya-ya > qala:ja > qala: }
\end{array}
$$

Aquí dos morfemas se han reducido a vocal alargada

$$
\text { qillqasina: 'al escribir' }
$$

148 Lengua \& Sociedad, vol. 18, n. ${ }^{\circ}$ 1, Lima, enero-junio de 2019 
La argumentación lingüistica, una guía para el estudio del alargamiento...
qilliqa: sina
'al ser escrito'

En estos ejemplos notamos aparente oposición, pero el alargamiento es por verbalización.

\subsection{Retorno, fundamento, base (Backing)}

Establece la validez general del garantizador. Se trata de un principio general del cual el garantizador sería una manifestación concreta.

En este estudio aparece como el marco conceptual, donde tenemos las siguientes bases:

- En la lengua quechua: «específicamente la cantidad vocálica está relacionada a debilitamiento o a elisión consonántica...» (Solis, 1996, p. 35).

- «Dos consonantes contiguas son reemplazadas por una simple que comparte rasgos de las dos primeras» (Schane, 1979, p. 81).

- «Alargamiento compensatorio es por elisión de un segmento en posición intervocálica geminada» ( $\mathrm{v}_{\mathrm{C} v \mathrm{l}} \rightarrow \mathrm{v}$ :). Asimismo elisión de segmento entre vocales diferentes (v1cv2 $\rightarrow$ v:) Finalmente el alargamiento compensatorio es por elisión de un segmento en posición inicial del grupo consonántico vCCV $\rightarrow$ v: Cv" (Versión adaptada de Beltzung, 2008, pp. 120, 130).

\section{CONCLUSIONES}

Por lo expuesto, podemos concluir que la conceptualización de R. Botha (1970) sobre la argumentación lingüística es aplicable a nuestro estudio sobre el carácter del alargamiento vocálico en el aimara y nos ha permitido validarlo.

En nuestra investigación hemos podido concluir con seguridad lo siguiente:

I. Las vocales alargadas son de carácter derivado, tanto en raíces, como en palabras sufijadas.

II. Las vocales alargadas se dan por:

1. Alargamiento compensatorio, cuando el segmento que se evapora está entre vocales idénticas, se encuentra en inicial del grupo consonántico o está entre vocales diferentes.

2. Los sufijos de verbalización, de tiempo futuro y de tiempo pasado que se presentan con consonantes [+continuo] donde el segmento se elide y se presenta la vocal alargada. 


\section{Felipe Huayhua Pari}

3. Cuando en las frases adverbiales hay juntura o sandhi de vocales, para evitar la formación de diptongos, se presenta la coalescencia y la vocal queda alargada.

4. El acento prosódico se confunde con alargamiento, tanto en los préstamos como en las formas paralingüísticas.

5. El reanálisis da lugar al falso alargamiento del acento prosódico de palabras prestadas del español y del quechua.

\section{Referencias Bibliográficas}

Ayala, J. L.. (1988).Diccionario Español-Aymara, Aymara-Español. Lima: Ed. Juan Mejía Baca.

Barraza, S. (2018). Cristobal Vaca de Castro, ordenanza de tambos (1543). Lima: Grafiluz.

Bertonio, L. (1603). Arte y gramática muy copiosa de la lengua Aymara. Roma: Zannetti.

Bertonio, L. (1612). Vocabulario de la lengua Aymara. Juli: Francisco del Canto.

Briggs, L. T. (1976). Dialectal Variation in the Aymara Language of Bolivia and Perú (Tesis docoral). Universidad de Florida, United States.

Botha, R. (1970). The Methodological Status of Grammatical Argumentation. La Haya: Mouton de Gruyter.

Cerrón-Palomino, R. (2001). Lingüística aimara. Cuzco: Bartolomé de las Casas.

Chene, B. y A. de. (1979). Compensatory Lengthening. En Language, 55, 3.

Church of Jesús Christ of Latter-day Saints. (1978). Asqui yatiyawin yatichawinacapa. US: Salt Lake City, Utah.

Deza, J. F. (1989). Nuevo diccionario Aymara-Castellano, Castellano-Aymara. Lima: Artex.

Deza, J. F. (1992). Gramática de la Lengua Aymara. Lima: Artex.

Hardman, M., Vasques, J., et al. (1974). Aymara: Compendio de estructura fonológica, gramatical. La Paz: ILCA.

Hardman, Martha, Vasques, J., et al. (1974-1988). Aymara Compendio de estructura fonológica y gramatical. La Paz: Gramma Impresión.

Herrero, J., \& Cotari, D. (1972). Lecciones de Aymara, $1 .^{\circ}$, 2. $^{\circ}$ nivel. Cochabamba: Instituto de Idiomas Padres de Maryknol.

Huayhua, F. (1991). El sistema deíctico verbal del aimara (Tesis de licenciatura). Universidad Nacional Mayor de San Marcos, Lima. 
Laargumentaciónlingüística, unaguíaparaelestudiodelalargamientovocálicoenaimara

Huayhua, F. (2001). Gramática descriptiva de la lengua aimara. Lima: Arco Iris. Martín, L. (1974). La fonología. En M. Hardman, ymara Compendio de estructura fonológica y gramatical. La Paz: Gramma Impresión.

Matthews, P. H. (1980). Morfología. Introducción a la estructura de la palabra. Madrid: Paraninfo.

Miranda, P. (1970). Diccionario Breve Castellano-Aymara y Aymara-Castellano. La Paz: El siglo.

Ross, E. H. (1953). Rudimentos de gramática aymara. La Paz: Canadian Baptist Mission.

Schane, A. (1979). Introducción a la fonología generativa. Barcelona: Labor.

Solis, G. (1996). Los orígenes de la cantidad vocálica en quechua. Lima: CilA.

Vaca de Castro, C. (1989 [1543]). Ordenanza de tambos. En Boletín de la Sociedad Geográfica de Lima, 104, 221-233. 